\title{
Assessment of vegetation degradation in arid regions by FA0/UNEP (Case study: Kashan Subbasin)
}

\author{
Morteza Abtahi 1, *, Mohammad Darvish ${ }^{2}$ \\ ${ }^{1}$ Research Division of Natural Resources, Isfahan Agricultural and Natural Resources Research and Education Center, \\ AREEO, Isfahan, Iran \\ 2Desert Research Division, Research Institute of Forests and Rangelands, AREEO, Tehran, Iran
}

\section{A R T I C L E I N F O}

\section{Article history:}

Received 2 June 2016

Received in revised form

25 July 2016

Accepted 25 July 2016

Keywords:

Desertification

Current Status

Inherent Risk

Vegetation

GIS

\begin{abstract}
A B S T R A C T
The increasing trend of desertification during the twentieth century, especially in the years after World War II, caused that international specialized organizations tried to inhibit this trend by applying proper and scientific management. Presenting a model for desertification assessment and providing the map of land susceptibility to the processes, reducing the efficiency of land, by FAO/UNEP was among these actions. A provisional methodology for assessment and mapping of desertification was formulated (FAO/UNEP, 1984) and is now used for local and regional assessment and mapping. The aim of the present study was to assessment of vegetation degradation from the aspect of current status and inherent risk is one of the proposed processes, corrected by considering the conditions of the study area, available information, and several sessions with the experts of rangeland and desert research divisions, Research Institute of Forests and Rangelands of Iran. From the aspect of current status, the vegetation degradation rate was calculated through measuring the canopy cover percentage of perennial species, rangeland quality, and forage production. From the aspect of inherent risk, it was calculated based upon the map of soil temperature and moisture regimes as well as information obtained from land capability map. Results showed that the degree of vegetation degradation in terms of current status for around $74 \%$ of the study area was very severe, while in terms of inherent risk it was severe and very severe for $84 \%$ of the study area. Our results clearly indicate the degradation of vegetation in northeast of Isfahan province, sounding the alarm.
\end{abstract}

(C) 2016 The Authors. Published by IASE. This is an open access article under the CC BY-NC-ND license (http://creativecommons.org/licenses/by-nc-nd/4.0/).

\section{Introduction}

Desertification is among the processes, reducing land efficiency and increasing the quality and quantity of environmental pollution with an increasing speed. Due to such a reducing phenomenon, at the dawn of the third millennium in which the number of inhabitants of the earth is over 6 billion people, international planners and world elite has encountered a big challenge, in the name of famine and malnutrition. That is why the United Nations has formally classified desertification in the category of the most important challenges of the current era.

\footnotetext{
* Corresponding Author.

Email Address: morabtahi70@gmail.com (M. Abtahi) http://dx.doi.org/10.21833/ijaas.2016.07.009

2313-626X/@ 2016 The Authors. Published by IASE.

This is an open access article under the CC BY-NC-ND license

(http://creativecommons.org/licenses/by-nc-nd/4.0/)
}

Due to desertification, the land productivity potential is declining rapidly and it will continue to deteriorate. According to the estimates of international organizations, annually, around 14 billion tons of crop production is lost worldwide due to the environmental degradation (land degradation, soil erosion, etc.). Therefore, knowing the exact quality of distribution and the ways of combating desertification is among the goals and policies of the United Nations to be implemented by environmental organizations.

Consequently, a provisional methodology for assessment and mapping of desertification was formulated (FAO/UNEP, 1984) and is now used for local and regional assessment and mapping (Darvish, 1999; FAO, 1984). In this method, seven natural processes were introduced as the indicators of desertification including: vegetation degradation, water erosion, wind erosion, soil salinization, decline in soil organic matter, crust formation and soil 
compaction, and accumulation of toxic substances in the soil for plants and animals.

Among the above processes, the first four ones play an important role and the next three processes are considered as sub-components of desertification (Meshkat, 1998). The reason is related to the extent of the four processes as well as their more effective role in reducing land productivity. In addition to the seven natural processes mentioned above, two other processes are presented in the method with human origin including livestock and population pressure on the environment. The above processes are evaluated from three aspects of current status, inherent risk and speed. In this paper, the vegetation degradation process is investigated from the aspect of current status and inherent risk.

In addition to FAO/UNEP, many scientists and researchers have suggested several methods for qualitative and quantitative assessment of the desert. Contrary to FAO/UNEP, highlighting the role of human pressure in the assessment of land desertification processes, Ahmadi (1995) just considered three criteria important in the development and formation of deserts including climate, geology and vegetation-ecology. Kardavani introduced climate as the sole distinctive feature in desert formation. However, any single-dimensional view to this phenomenon has been rejected explicitly by Servati (1995). Ekhtesasi and Mohajeri (1995) tried to provide a more realistic assessment of desertification process. They introduced a method based upon research needs and environmental, social and economic structures of the deserts of Iran, registered in 1995 (abbreviated as I.D.C).

In this method, eight indicators effective in desertification were introduced including: three environmental indicators (climate, geology and the quantity and quality of water and soil resources; three human indicators (vegetation degradation, water resources degradation and land and soil degradation) and finally the severity of soil erosion and the potential of ecosystem restoration.

Babaev (1993) presented a new method to provide the maps indicating the effective functions in the process of land degradation at 1:2500000 scales. The area of the study area was two million square kilometers in which the Aral Sea exists. Abbasabadi (1999) investigated the desertification in Aqqala Plain and determined the share of desertification factors. Contrary to the findings reported by Babaev (1993), he stated that flooding of lands in this region had more determinant role in the formation and intensification of the processes reducing the efficiency of land; however, the latter factor aggravates soil salinization, which is another main indicator of desertification.

According to Abbasabadi (1999), geology is more important as compared to other natural factors, and among human factors, uncontrolled exploitation of natural resources, especially overgrazing, is the most important desertification factor. Wangati (1997) by considering the indicators effective in land degradation prepared the risk map of different regions of Kenya using FAO/UNEP. They stated that the desertification of $1 \%, 13 \%, 53 \%$, and $33 \%$ of the territory was very severe, severe, moderate and slight, respectively. Harasheh and Tateshi (2000) prepared the desertification map in West Asia using FAO/UNEP Vegetation degradation, water and wind erosion, and soil salinity were detected as the most important factors of desertification. Ladisa et al. (2002), in assessing the desertification of Bari region in Italy, investigated six indicators including soil, vegetation, land use, management and human pressures and provided the final map of desertification using the geometric mean of indicators. Meshkat (2006) provided the map of vegetation degradation, wind erosion, and saline lands for a part of Yazd-Ardakan Plain. He concluded that currently the degrees of vegetation degradation, salinity and wind erosion were severe to very severe, moderate to severe and slight to moderate, respectively. The inherent risk of these three processes was very sever, moderate to severe, and moderate to severe, respectively. The severity of desertification Sistan plain of Iran was evaluated using the model IMDPA ${ }^{\dagger}$. In this study, 4 factor climate, wind erosion, soil and vegetation identified that are the most important factors in desertification (Zolfaqari et al., 2011).

This research was aimed to apply the modified FAO/UNEP to assess vegetation degradation in arid and desert regions of the country and presenting the results of applying the mentioned method in one of the arid regions. The main question of the study was to determine vegetation degradation in arid regions by modified FAO/UNEP method.

\section{Materials and methods}

\subsection{Characteristics of the study area}

The study area is located in the east of Salt Lake Watershed (Basin). This area covers half of the city of Qom, more than 80 percent of the area of Kashan, Aran and Bidgol, and a part of the city of Natanz and Garmsaar. The maximum altitude of this area is 3588 $\mathrm{m}$ (Karkas Mountain) in the southern altitudes and the minimum is $800 \mathrm{~m}$ in the Salt Lake, and the total area is around one million and six hundred thousand hectare $\left(10000 \mathrm{~m}^{2}\right)$.

A number of rivers, with a low watershed area, are originated from the northern slopes of the Karkas Mountains, flowing to the Kashan plain and the Salt Lake. Due to the severe shortage of rainfall in these altitudes, these rivers generally have a very little discharge and except in cases of exceptional floods, all water is used in the watershed and foothills as irrigation and penetration into the aquifer (groundwater).

The climate of the study area varies due to the wide altitudinal range. According to the meteorological data of Kashan synoptic station, an average annual rainfall of $137 \mathrm{~mm}$, average annual

† Iranian Model for Desertification Potential Assessment 
temperature of $18.9{ }^{\circ} \mathrm{C}$, minimum annual evaporation of 2100 and maximum of $3162 \mathrm{~mm}$ are reported. The climate of the study area is hyperarid based on the De Martonne method (aridity index=4.7).

The Salt Lake is a large and spacious pan which is the terminal of a large number of surface and underground flows in the northwest of Central Iran Watershed. The drainage waters of Tehran - Karaj Plain and the surplus water of the Karaj-Jajrud, Shoor Qazvin, Gharechai and Ghomrood rivers and a large number of streams and waterways pour to it and lost through evaporation.

\subsection{Methodology}

Vegetation degradation in terms of current status and inherent risk was assesses based on the modified FAO and UNEP method, resulting from various scientific meetings attended by professors and researchers with experience in range management and combat desertification at the Research Institute of Forests and Rangelands of Iran.

This method was provided in the form of the description of services for the national project of desertification assessment and mapping by FAO and UNEP method in the Salt Lake watershed in central of Iran (Darvish, 2007).

The vegetation deterioration in terms of current status was assessed and scored by measuring the canopy cover percentage of perennial plants, rangeland quality and forage production in each vegetation type (Table 1 ).

Table 1: Assessment of vegetation degradation in terms of current status

\begin{tabular}{|c|c|c|c|c|}
\hline & \multicolumn{4}{|c|}{ Degree and Weight of desertification } \\
\hline Plant Index & Slight (2.5) & Medium (5) & Severe (7.5) & $\begin{array}{c}\text { Extremely Sever } \\
(10)\end{array}$ \\
\hline $\begin{array}{l}\text { canopy cover } \\
\text { percentage of } \\
\text { perennial plants }\end{array}$ & $>30$ & $20-30$ & $10-20$ & $<10$ \\
\hline rangeland quality & $\begin{array}{l}\text { High quality species } \\
\text { coupled with the medium } \\
\text { and the number of species } \\
\text { worth less than } 25 \text { per cent }\end{array}$ & $\begin{array}{l}\text { The average species alone or } \\
\text { combined with a low-value species } \\
50-25 \% \text { are the dominant vegetation } \\
\text { composition amounted }\end{array}$ & $\begin{array}{l}\text { Low-value species } \\
\text { dominant coverage } \\
\text { amounted } 50-75 \% \text {. }\end{array}$ & $\begin{array}{l}\text { Low-value } \\
\text { species is } \\
\text { greater than } \\
75 \% \text { coverage of } \\
\text { the dominant }\end{array}$ \\
\hline $\begin{array}{l}\text { forage production } \\
\qquad\left(\mathrm{kg} / \mathrm{m}^{2}\right)\end{array}$ & $>0.02$ & $0.01-0.02$ & $0.005-0.01$ & $<0.005$ \\
\hline
\end{tabular}

Inherent risk or in other words inherent vulnerability of land from the viewpoint of vegetation degradation could be calculated according to the concepts embodied in the temperature and moisture regimes (Ammari, 1991) as well as the information obtained from land capability map.

First, the land units and types of Kashan watershed were identified and then after consultation with experts, their classification and weighting was done according to the soil texture and depth, salinity and alkalinity limitations (Malakoti and Homaee, 1994) and erosion as described in Table 2 .

Classification and weighting of soil moisture regimes and soil thermal regimes are presented in Tables 3 and 4, respectively.
Table 2: Classification and weighting of the land units related tothe land types of land capability map

\begin{tabular}{|c|c|c|}
\hline Weight & Class & Land Unit \\
\hline 1 & Low (1) & $4.1,4.2,4.5$ \\
\hline \multirow{2}{*}{1.33} & Medium (2) & $\begin{array}{c}2.5,4.6,4.7,7.1,8.1,8.2,9.2, \\
9.3, \mathrm{C} 2, \mathrm{C} 3, \mathrm{X} 3\end{array}$ \\
\hline \multirow{2}{*}{1.66} & Sever (3) & $\begin{array}{c}2.2,2.3,3.1,3.2,3.3,3.5,7.2, \\
7.5,9.1, \mathrm{C} 1\end{array}$ \\
\hline \multirow{2}{*}{2} & Extremely & $\begin{array}{c}1.1,1.2,1.3,1.4,2.1,2.4,3.4, \\
4.3,4.4,6.1,6.2,6.3,6.4,6.5 \\
7.3,7.4, \mathrm{X} 1, \mathrm{X} 2\end{array}$ \\
\hline
\end{tabular}

It should be noted that here, too, the classification of each moisture and thermal regimes in the relevant class was performed in consultation with the experts.

Table 3: Classification and weighting of soil moisture regimes

\begin{tabular}{|c|c|c|}
\hline Moisture Regimes & Class & Weight \\
\hline Udic & Low (1) & 1 \\
\hline Xeric and Ustic & Medium (2) & 1.33 \\
\hline Weak Aridic & Sever (3) & 1.66 \\
\hline Typic Aridic and Extreme Aridic & Extremely Sever (4) & 2 \\
\hline
\end{tabular}

Table 4: Classification and weighting of soil thermal regimes

\begin{tabular}{|c|c|c|}
\hline Termal Regimes & Class & Weight \\
\hline Mesic & Low (1) & 1 \\
\hline Thermic & Medium (2) & 1.33 \\
\hline Frigid & Sever (3) & 1.66 \\
\hline Hyper Thermic & Extremely Sever (4) & 2 \\
\hline
\end{tabular}

The final map was obtained from the geometric means of three mentioned maps in the Elvis (Table 5). It should be noted that statistics experts believe that using geometric mean is the best for the combination of indicators together (Kosmos et al., 1999). 
Table 5: Weight classes of rangeland inherent vulnerability

\begin{tabular}{|c|c|}
\hline Class & Weight Range \\
\hline Low (1) & $1-1.25$ \\
\hline Medium (2) & $1.25-1.5$ \\
\hline Sever (3) & $1.5-1.75$ \\
\hline Extremely Sever (4) & $1.75-2$ \\
\hline
\end{tabular}

\section{Results and discussion}

Maps 1-3 show the canopy cover percentage, rangeland quality and forage production according to the above-mentioned method, respectively, divided into four classes.

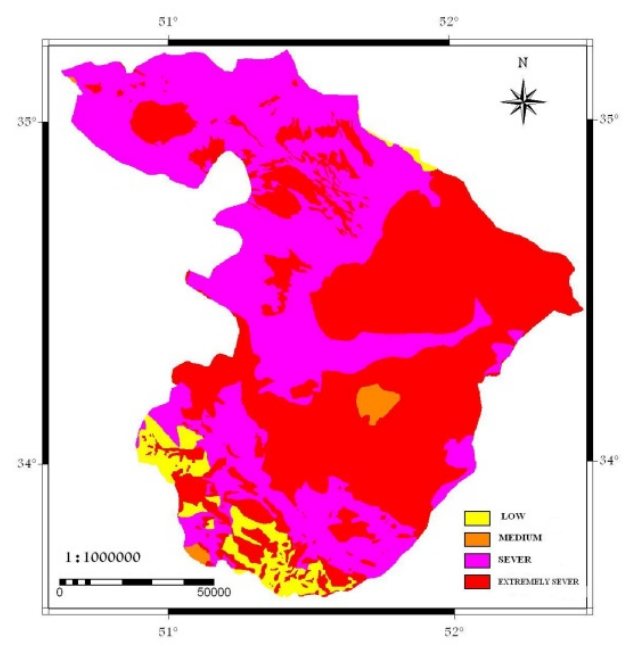

Fig. 1: Canopy cover percentage of perennial plants

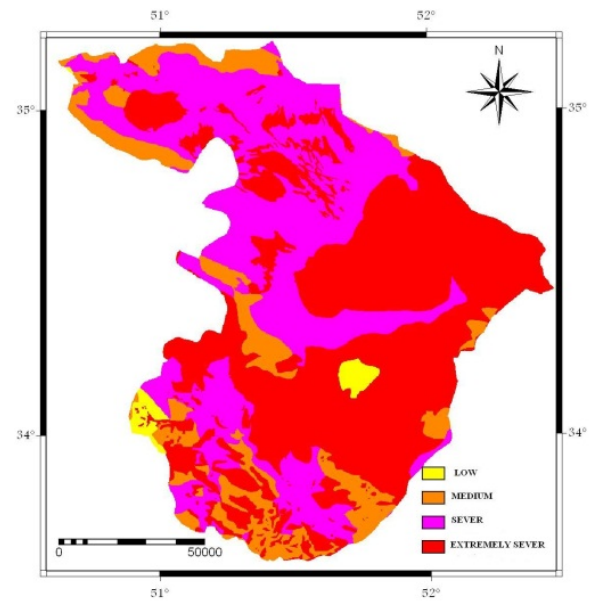

Fig. 3: Forage production

The classification and zonation of land types and units, soil moisture regimes, and soil thermal regimes, in the land capability map, are presented in Maps 5-7. Map 8 shows vegetation degradation in terms of inherent risk, obtained from the geometric means of above-mentioned indicators. The area and the percentage of each class to the total watershed are given in Table 7 (Figs. 5-8).

Two issues must be taken into consideration for combating desertification including current status,
Map 4 was prepared from the geometric means of three above maps in the Elvis, showing vegetation degradation in terms of current status, and the area and percentage of each class was calculated (Table 6 and Figs. 1-4).

Table 6: Area and classes of vegetation degradation map in terms of current status (Ha)

\begin{tabular}{|c|c|c|c|c|}
\hline Class & Low & Medium & Sever & $\begin{array}{c}\text { Extremely } \\
\text { Sever }\end{array}$ \\
\hline Area(Ha) & 12364 & 66120 & 331600 & 1164256 \\
\hline Percent (\%) & 0.78 & 4.2 & 21.07 & 73.95 \\
\hline
\end{tabular}

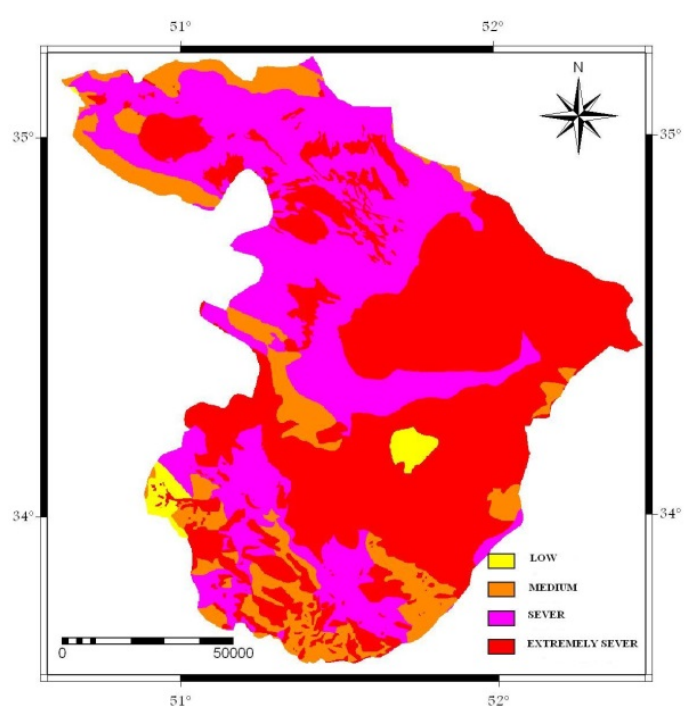

Fig. 2: Rangeland quality

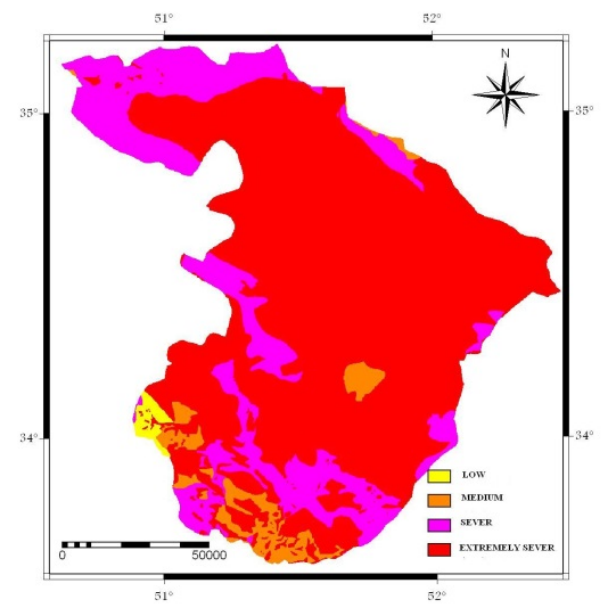

Fig. 4: Vegetation degradation map in terms of current status

referring to the environment and human performance, and inherent risk.

The resultant of these two forces is a situation that we see now. Therefore, most of our task is to reform the management and utilization. Our solutions should be able to reduce the pressure caused by humans as well as environmental stresses as far as possible.

As can be observed from the parameters involved in the evaluation of the inherent risk of the region, 
we are dealing with environmental factors. These factors are under the influence of precipitation, temperature, and soil suitability.

Our results clearly showed that the study area had no favorable conditions in terms of current status since the degradation of more than $75 \%$ of the region was very sever while there was just slight degradation for $0.75 \%$ of the study area. Our results are in accordance with the finding of Farmahini and
Darvish (2013) that vegetation degradation and water erosion were identified as the main factors of desertification in this basin of Arak (Iran) and livestock grazing was the main cause of worsening desertification. The results of study Ahmadian et al. (2014) showed that the highest vegetation decline (76\%) was observed in the east, south, and center of the Gharachay of Iran.

Table 7: Area and classes of vegetation degradation map in terms of inherent risk (ha)

\begin{tabular}{c|c|c|c|c|} 
Class & Low & Medium & Sever & Extremely Sever \\
Area(Ha) & 11106 & 238198 & 621834 & 703202 \\
Percent (\%) & 0.71 & 15.13 & 39.50 & 44.66 \\
\hline
\end{tabular}

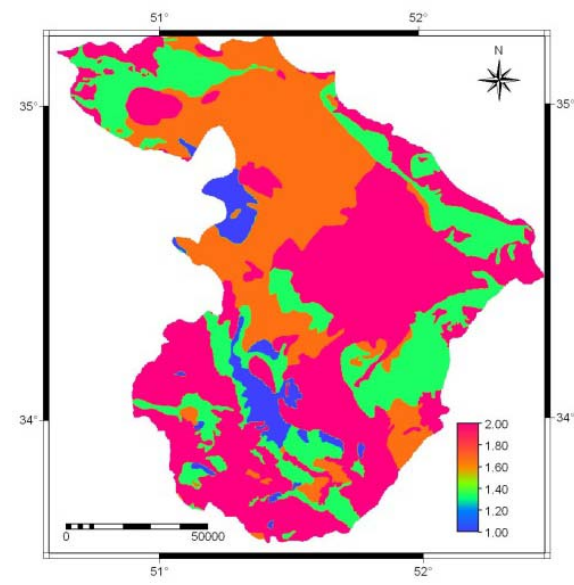

Fig. 5: Land capability map

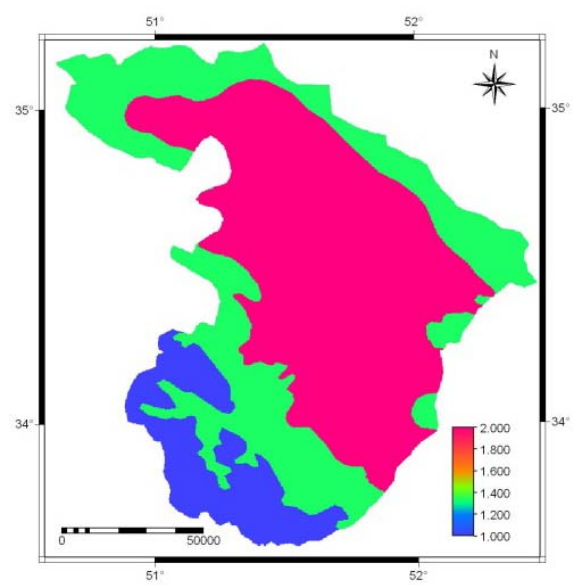

Fig. 7: Soil thermal regimes

Therefore, these results remind us of inappropriate management of exploitation from the past to the present.

Before any reclamation practices, the type and severity of vegetation exploitation should be reconsidered since this type of exploitation makes any reclamation fail.

In the case of true statistics, according to the maps of range allotments, more than $60 \%$ of the region is under severe and very severe grazing pressure (Abtahi, 2008).

Therefore, in the discussion of reclamation, before heavy spending of costs and applying a variety of techniques to combat land degradation, new range management should be employed.

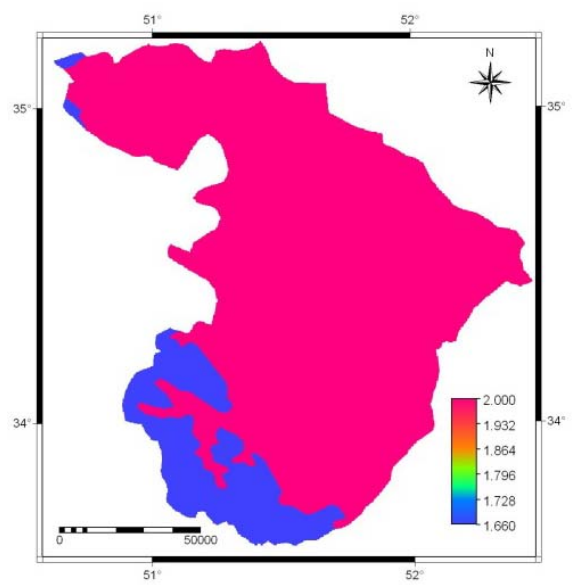

Fig. 6: Soil moisture regimes

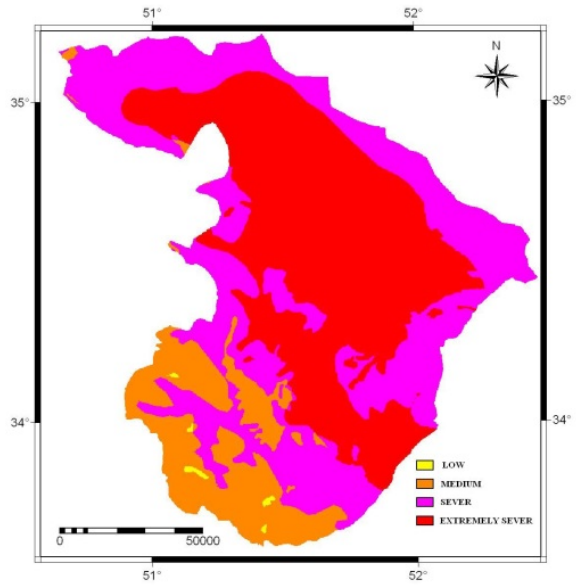

Fig. 8: Vegetation degradation map in terms of inherent risk

In the second stage, we should have a look at the natural potential of the region. Since more than $85 \%$ of the watershed is under poor natural conditions in terms of soil, precipitation and temperature.

In total, the method applied to evaluate the vegetation degradation, from the aspect of current status and inherent risk, could be recommended for other parts of the country with an arid and semi-arid climate.

\section{References}

Abbasabadi MR (1999). Desertification assessment in plain Aqqala Gomishan in order to provide a 
regional model. M.Sc. Thesis of the desert, Tehran University, Tehran, Iran. 250 p.

Abtahi SM (2008). Evaluation and preparation of the map with FAO and UNEP desertification in the Kashan basin plan. Forest and Rangeland Research Institute Publications, $158 \mathrm{p}$. http://www.rifr-ac.org/EN/Default.aspx.

Ahmadi H (1995). The Iranian deserts recognition criteria. Second Conference on Desertification and the Methods of Combating Desertification, Kerman, Iran.

Ahmadian M, Darvish $\mathrm{M}$ and Sadeghimanesh MM (2014). Assessment and mapping the total risk of desertification using fao and unep modified method (Case study: Gharachay watershed). Iranian Journal of Range and Desert Research. 21(4): 604-619.

Ammari P (1991). Appeal on a map of soil moisture and thermal regimes of Iran. M.Sc. Thesis, Faculty of Agriculture, University of Tehran, Tehran, Iran.

Babaev AG (1993). Assessment and mapping of desertification processes: A methodological guide. Desert research Institute, Academy of Sciences of Turkmenistan, Ashkabad.

Darvish M (1999). Management feasibility study on desertification mapping method on the Fao and Unep method in Iran. M.Sc. Thesis, Science and Research Branch, Islamic Azad University, Tehran, Iran.

Darvish M (2007). Description of the national project of evaluation and design services map of desertification FAO and UNEP methods revised in the salt lake basin. Forest and Rangeland Research Institute Publications, 27 p. http://www.rifr-ac.org/EN/Default.aspx.

Ekhtesasi MR and Mohajeri S (1995). The methodology of classification, quality and severity of desertification in Iran. Second Conference on Desertification and the Methods of Combating Desertification, Kerman, Iran.

FAO (1984). Provisional methodology for assessment and mapping of desertification. Food and Agriculture Organization of the United Nations and United Nations Environment Programme, Rome, Italy. 85p. http://trove.nla.gov.au/version/27017559.
Farmahini FA and Darvish M (2013). assessment and generating desertification map using FAO and UNEP method in kavire-e-meighan. Iranian Journal of Range and Desert Research. 4(49): 547-556.

Harasheh H and Tateishi R (2000). Desertification mapping of west Asia by GIS and remote sensing application. (Available at: http://www.gisdevelopment.net/aars/acrs).

Kosmas C, Gerontidis ST, Detsis V, Zafiriou TH, and Marathianou M (1999). Application of the MEDALUS methodology for defining ESAs in the Lesvos Island. European Commission., Capri, Italy, June: 24-28.

Ladisa G, Todorovic M, and Trisorio_liuzzi G (2002). Characterization of area sensitive to desertification in southern Italy. In Proceeding of the $2^{\text {nd }}$ International Conference on New Trend in Water and Environmental Engineering for Safety and Life: Eco-compatible solutions for Aquatic Environmental, Capri, Italy.

Malakoti MJ and Homaee M (1994). Arid lands soils fertility, Problems and solving ways. Tarbiat Modarres University Publications, Tehran, Iran.

Meshkat MA (1998). Temporary method for the evaluation and preparation of the map of desertification. Forest and Rangeland Research Institute Publications, 104 p., http://www.rifrac.org/EN/Default.aspx.

Meshkat MA (2006). Mapped deterioration of vegetation, wind erosion and salt lands for the part of Yazd, ardakan Plains, Journal of Range and Desert Research. 13(1): 10-16.

Servati, MR (1995). Desert and geomorphology. Second Conference on Desertification and the Methods of Combating Desertification, Kerman, Iran.

Wangati F (1997). Developing the capacity for national desertification assessment, A Kenya study. World Atlas of Desertification, 2: 110-113.

Zolfaqari F, Shahriyari A, Fakhireh A, Rashki A, Noori $\mathrm{S}$ and Khosravi H (2011). The Assessment of desertification severity in Sistan plain using IMDPA model. Watershed Management Researches, 91: 97-107. 